\begin{tabular}{|c|c|}
\hline Title & Carrier dynamics and photoluminescence quenching mechanism of strained InGaSb/A IGaSb quantum wells \\
\hline Author(s) & $\begin{array}{l}\text { Jahan, Nahid A .; Hermannstaldter, Claus; Sasakura, Hirotaka; Rotter, Thomas J.; A hirwar, Pankaj; Bal akrishnan, } \\
\text { Ganesh; Kumano, Hidekazu; Suemune, I kuo }\end{array}$ \\
\hline Citation & $\begin{array}{l}\text { Journal of A pplied Physics, 113(5), } 053505 \\
\text { https://doi.org/10.1063/1.4789374 }\end{array}$ \\
\hline Issue Date & $2013-02-07$ \\
\hline Doc URL & http:/hdl.handle.net/2115/54789 \\
\hline Rights & $\begin{array}{l}\text { Copyright } 2013 \text { A merican Institute of Physics. This article may be downloaded for personal use only. A ny other use } \\
\text { requires prior permission of the author and the A merican Institute of Physics. The following article appeared in Journal } \\
\text { of A pplied Phy sics } 113(5) 053505 \text { and may be found at } \\
\text { http://scitation.aip.org/content/aip/ournal Jap } 113 / 5 / 10.1063 / 1.4789374 \text {. }\end{array}$ \\
\hline Tyре & article \\
\hline File Information & 314-JA P13-Nahid InGaSb QW .pdf \\
\hline
\end{tabular}

Instructions for use 


\title{
Carrier dynamics and photoluminescence quenching mechanism of strained InGaSb/AIGaSb quantum wells
}

\author{
Nahid A. Jahan, ${ }^{1,2, a)}$ Claus Hermannstädter, ${ }^{1}$ Hirotaka Sasakura, ${ }^{1}$ Thomas J. Rotter, ${ }^{3}$ \\ Pankaj Ahirwar, ${ }^{3}$ Ganesh Balakrishnan, ${ }^{3}$ Hidekazu Kumano, ${ }^{1}$ and Ikuo Suemune ${ }^{1}$ \\ ${ }_{1}^{1}$ Research Institute for Electronic Science, Hokkaido University, Sapporo 001-0021, Japan \\ ${ }^{2}$ Graduate School of Information Science and Technology, Hokkaido University, Sapporo 060-0814, Japan \\ ${ }^{3}$ Center for High Technology Materials, University of New Mexico, 1313 Goddard SE, Albuquerque, \\ New Mexico 87106, USA
}

(Received 4 November 2012; accepted 8 January 2013; published online 5 February 2013)

\begin{abstract}
GaSb based quantum wells (QWs) show promising optical properties in near-infrared spectral range. In this paper, we present photoluminescence (PL) spectroscopies of $\operatorname{In}_{\mathrm{x}} \mathrm{Ga}_{1-\mathrm{x}} \mathrm{Sb} / \mathrm{Al}_{\mathrm{y}} \mathrm{Ga}_{1-\mathrm{y}} \mathrm{Sb} \mathrm{QWs}$ and discuss the possible thermal quenching and non-radiative carrier recombination mechanisms of the QW structures. The In and Al concentrations as well as the QW thicknesses were precisely determined with the X-ray diffraction measurements. Temperature dependent time-integrated and time-resolved PL spectroscopies resulted in the thermal activation energies of $\sim 45 \mathrm{meV}$, and the overall self-consistent calculation of the band parameters based on the measured physical values confirmed that the activation energies are due to the hole escape from the QW to the barriers. The relation of the present single carrier escape mechanism with the other escape mechanisms reported with other material systems was discussed based on the estimated band offset. The relation of the present thermal hole escape to the Auger recombination was also discussed. (C) 2013 American Institute of Physics. [http://dx.doi.org/10.1063/1.4789374]
\end{abstract}

\section{INTRODUCTION}

Near-infrared emitters can be used for a wide range of applications such as gas sensing, ${ }^{1}$ monitoring of environmental pollution such as carbon monoxide and phosphine, ${ }^{2-4}$ military scene projection, thermo-photovoltaic (TPV) devices, ${ }^{5,6}$ and low-loss fibre optical communication. ${ }^{7}$ Especially, vertical cavity surface emitting lasers (VCSELs) or vertical external cavity surface emitting lasers (VECSELs) have wide range of applications. Although InP-based edge emitting lasers have been in practical use in the telecommunication band, it is well known that high-efficiency distributed Bragg reflectors (DBRs) are difficult to grow on InP substrates. ${ }^{8,9}$ Since AlAs/GaAs DBRs are highly efficient, most of VCSELs and VECSELs have been studied on GaAs substrates. However, near-infrared lasers are generally difficult to achieve on GaAs substrates.

Concerning such applications, GaSb has received practical interest due to its narrow band-gap properties which offer potentiality in long-wavelength optoelectronic devices. ${ }^{10}$ For example, InGaSb/GaAs quantum dot (QD) VCSEL was operated at room temperature (RT) employing $\mathrm{AlAs} / \mathrm{GaAs}$ DBRs. ${ }^{11}$ Although Sb-based materials system is highly missmatched to GaAs substrates, interfacial $90^{\circ}$ misfit dislocations (IMF) technique was developed, ${ }^{12}$ which localizes the dislocation generation at the $\mathrm{GaSb} / \mathrm{GaAs}$ interface and prevents threading dislocations in overgrown Sb-based heterostructures. This IMF technique made RT laser operation of $\mathrm{InGaSb} / \mathrm{AlGaSb}$ quantum wells (QWs) possible on (001) GaAs substrate. ${ }^{13}$ The ternary InGaSb alloys are suitable to tailor wavelengths in the near infrared and longer wave-

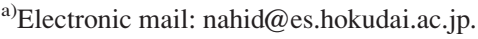

lengths over $2 \mu \mathrm{m} .{ }^{13-16}$ Recently, Lai et al. demonstrated $340-\mathrm{W}$ peak output at the wavelength of $2 \mu \mathrm{m}$ from an InGaSb/AlGaSb VECSEL operated at RT. ${ }^{17}$ Continuouswave $(\mathrm{CW})$ operation at RT was also achieved but the output power was limited to $0.12 \mathrm{~W} .{ }^{18}$ The main factor that limits the VECSEL maximum light output was heating due to nonradiative recombination. Therefore, it is crucial to extend our understanding of the non-radiative processes. To date, numbers of works have been carried out to clarify the nonradiative processes. Some suggested that non-radiative Auger recombination is the most detrimental mechanism which limits the performance of the low band-gap longwavelength semiconductor lasers. ${ }^{19-22}$ On the other hand, Shterengas et al..$^{23,24}$ and Rainò et al. ${ }^{25}$ reported that thermally induced hole escape is the main non-radiative process which deteriorates the optical properties and performances of the GaSb-based devices at elevated temperature.

Therefore, it is the purpose of this paper to clarify the role of the carrier escape in $\mathrm{In}_{\mathrm{x}} \mathrm{Ga}_{1-\mathrm{x}} \mathrm{Sb} / \mathrm{Al}_{\mathrm{y}} \mathrm{Ga}_{1-\mathrm{y}} \mathrm{Sb} \mathrm{QWs}$ and study the relation to the Auger recombination based on transient and CW luminescence measurements. The QW samples were precisely characterized by X-ray diffraction (XRD) measurements to determine the epitaxial layer thicknesses and compositions. The temperature dependent carrier recombination process was analysed by employing $\mathrm{CW}$ time-integrated and time-resolved photoluminescence (PL) spectroscopy. From the temperature dependence of the steady-state PL and decay time analyses, the thermal quenching energies of the QWs were extracted. Including the measured thicknesses of the QWs, the thermal activation energies, theoretically determined band deformation potential, and the transition energies as input parameters, the quantum confinement energies were calculated by solving the Schrödinger equation for finite 
potential wells. From these observations and analyses, we develop and quantify the whole energy band structure to explain the non-radiative mechanism responsible for PL quenching in our studied $\mathrm{InGaSb} / \mathrm{AlGaSb} \mathrm{QW}$ structures. Finally, the relation of the carrier escape mechanism to the Auger recombination is discussed.

\section{STRUCTURAL STUDY OF InGaSb/AIGaSb QWs BY X-RAY DIFFRACTION}

InGaSb QWs embedded in AlGaSb barrier matrix studied in this work were grown by solid-source molecular-beam epitaxy (MBE) on $\mathrm{GaSb}(001)$ substrates. The $\mathrm{In}_{\mathrm{x}} \mathrm{Ga}_{1-\mathrm{x}} \mathrm{Sb}$ QWs of around 3-nm thickness are surrounded by barrier layers of around 50-nm-thick $\mathrm{Al}_{\mathrm{y}} \mathrm{Ga}_{1-\mathrm{y}} \mathrm{Sb}$ and capped by 10-nm-thick GaSb layers on top. To examine the precise thicknesses and compositions of the QWs and barriers, XRD measurements were carried out using the Bruker D8 Discover high-resolution XRD system. The simulations of the $2 \theta-\omega$ scans reproduced the measurements very nicely as shown in Fig. 1(b), and the thicknesses of $2.9 \mathrm{~nm}$ and $3.4 \mathrm{~nm}$ with the respective indium (In) concentration of $32 \%$ and $36 \%$ for the two $\operatorname{In}_{\mathrm{x}} \mathrm{Ga}_{1-\mathrm{x}} \mathrm{Sb}$ QWs and the aluminium concentrations of $49 \%$ and $50 \%$ for the $\mathrm{Al}_{\mathrm{y}} \mathrm{Ga}_{1-\mathrm{y}} \mathrm{Sb}$ barrier layers were derived (the result on one of the samples is shown in Fig. 1). The derived parameters for one of the QWs are shown in Fig. 1(a).

\section{EXPERIMENTAL SET UP FOR PL MEASUREMENTS}

Time-integrated PL measurements were performed using non-resonant $\mathrm{CW}$ excitation at the low average power density of $5 \mathrm{~W} / \mathrm{cm}^{2}$ using a frequency doubled Nd:YAG laser emitting at $2.33 \mathrm{eV}(532 \mathrm{~nm})$. A He-Ne laser at $1.95 \mathrm{eV}$ $(633 \mathrm{~nm})$ was also used for the excitation. For the temperature dependent PL spectroscopy, a 30-cm monochromator with a rotating 200 groves $/ \mathrm{mm}$ grating and a liquid Nitrogen cooled InGaAs photodiode detector with the extended wavelength range up to $2.2 \mu \mathrm{m}$ were used in the lock-in operation and the excitation laser was modulated by a mechanical chopper.

Time-resolved PL spectroscopy was performed to investigate the temperature dependent carrier dynamics in the QWs. The $\sim 5$-ps optical pulses generated by a mode-locked Ti:sapphire laser tuned at $1.59 \mathrm{eV}(780 \mathrm{~nm})$ with a repetition rate of $76 \mathrm{MHz}$ were used for the excitation. A near-infrared streak camera (Hamamatsu C11293-01) combined with a
150 groves/mm monochromator was used for the detection of the time-resolved PL spectra with 20-ps time resolution. Because of the detection sensitivity limited to the wavelength below $1700 \mathrm{~nm}$, the present $\mathrm{InGaSb} / \mathrm{AlGaSb} \mathrm{QW}$ samples were designed to emit in the 1550-nm band.

\section{PL MEASUREMENTS AND DISCUSSIONS}

To study the thermal quenching mechanism of luminescence at elevated temperature, precise measurements and clear identification of its origin are inevitable. The carrier dynamics in the QWs is discussed quantitatively with the measurements of transient PL, together with the temperature dependent steady-state PL measurements in this section. Based on these results and their analyses, the fundamental QW band structures are determined and the luminescence quenching mechanism is discussed.

\section{A. Time-integrated PL measurements}

CW time-integrated PL measurements were performed on the two InGaSb QWs at $10 \mathrm{~K}$ under the low excitation power of $5 \mathrm{~W} / \mathrm{cm}^{2}$ using the YAG laser $(2.33 \mathrm{eV})$ and the measured spectrum of the $\mathrm{In}_{0.32} \mathrm{Ga}_{0.68} \mathrm{Sb} \mathrm{QW}$ is shown in Fig. 2(a). The PL peak energies to be discussed hereafter in this paper are obtained by employing Gaussian lineshape functions in multi-peak fitting. The dominant emission peak at $1508 \mathrm{~nm}(822 \mathrm{meV})$ is attributed to the optical transition in the $\mathrm{In}_{0.32} \mathrm{Ga}_{0.68} \mathrm{Sb}$ strained QW together with the later discussion. The emission peak centered at $1593 \mathrm{~nm}(778.3 \mathrm{meV})$ is associated with the donor-acceptor pair (DAP) transition usually observed in GaSb substrates $^{26,27}$ and its temperature dependence will be discussed later. The small emission peak at around $1557 \mathrm{~nm}$ $(796.1 \mathrm{meV})$ is attributed to the GaSb exciton bound to neutral acceptor $\left(\mathrm{BE} 4-\mathrm{A}^{0}\right)$ transition commonly reported in previous publications. ${ }^{26}$

To confirm the PL peak assignments associated with impurities in the GaSb substrate, we replaced the YAG laser with a He-Ne laser with the lower photon energy of $1.95 \mathrm{eV}$. The InGaSb absorption coefficient at the photon energy of $\sim 2 \mathrm{eV}$ is estimated to be $\alpha \sim 10^{5} \mathrm{~cm}^{-1}$, and then the laser penetration depth is $1 / \alpha \sim 100 \mathrm{~nm}$. Our present QW samples have the total AlGaSb barrier thickness of $\sim 100 \mathrm{~nm}$ that is the same order with the laser penetration depth. Therefore, the injection of photo-generated carriers into the GaSb substrate and the observation of the PL from the GaSb substrate (a)

\begin{tabular}{|c|}
\hline $\mathrm{GaSb}$ caplayer $(10 \mathrm{~nm})$ \\
\hline $\mathrm{Al}_{0.49} \mathrm{Ga}_{0.51} \mathrm{Sb}(49 \mathrm{~nm})$ \\
\hline $\mathrm{In}_{0.32} \mathrm{Ga}_{0.68} \mathrm{Sb}(2.89 \mathrm{~nm})$ \\
\hline $\mathrm{Al}_{0.49} \mathrm{Ga}_{0.51} \mathrm{Sb}(49 \mathrm{~nm})$ \\
\hline $\mathrm{GaSb}$ \\
\hline
\end{tabular}

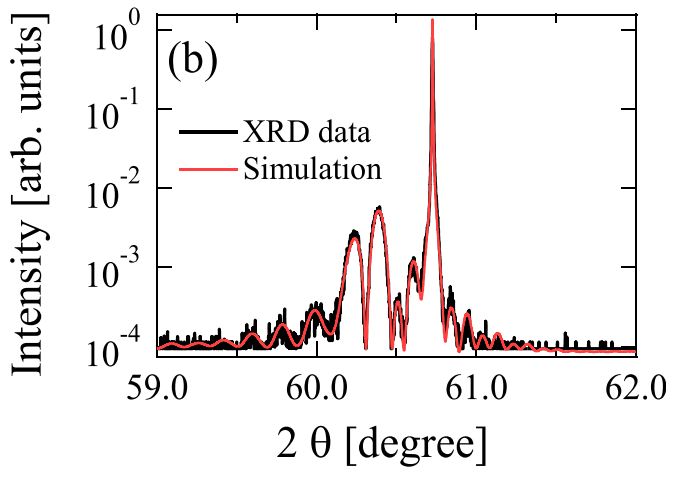

FIG. 1. (a) Schematic illustration of the

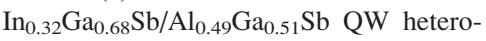
structure grown on a $\mathrm{GaSb}$ substrate. (b) The measured XRD curve and simulation of $2 \theta-\omega$ scan using the Bruker D8 Discover high-resolution XRD system exemplarily shown for the case of $\mathrm{In}_{0.32} \mathrm{Ga}_{0.68} \mathrm{Sb} / \mathrm{Al}_{0.49} \mathrm{Ga}_{0.51} \mathrm{Sb}$ QW. 

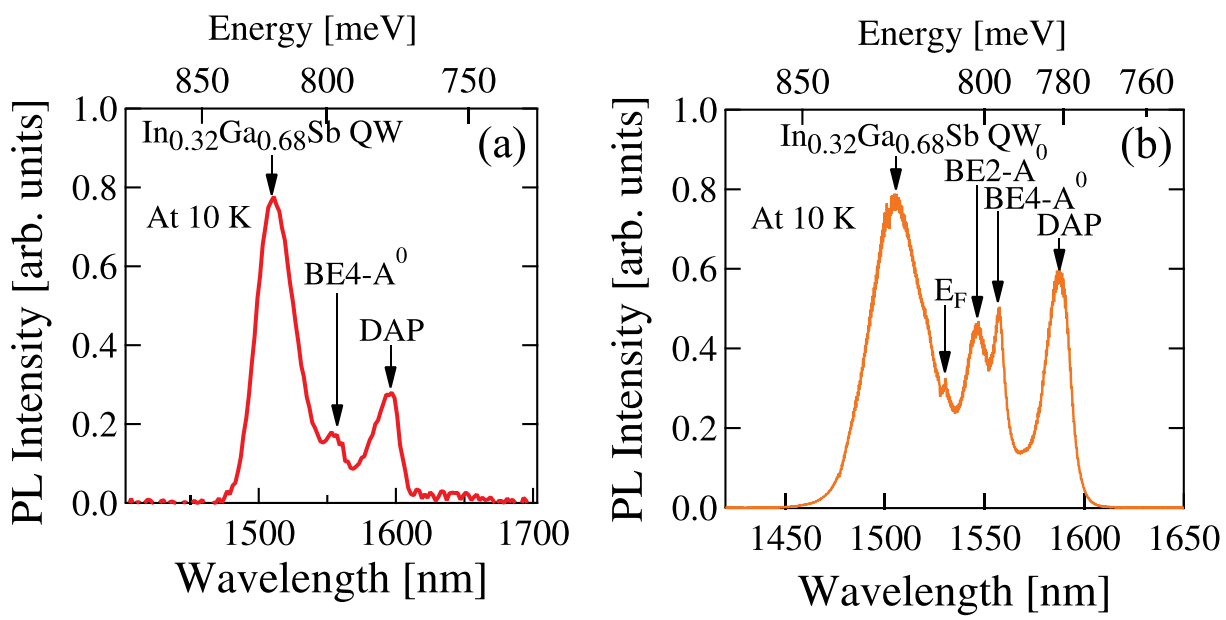

FIG. 2. (a) $10 \mathrm{~K}$ PL spectrum of $\mathrm{In}_{0.32} \mathrm{Ga}_{0.68}$ $\mathrm{Sb} / \mathrm{Al}_{0.49} \mathrm{Ga}_{0.51} \mathrm{Sb}$ QW under low power non-resonant excitation of $5 \mathrm{~W} / \mathrm{cm}^{2}$ using $\mathrm{Nd}: \mathrm{YAG}$ laser $(2.33 \mathrm{eV})$. (b) $10 \mathrm{~K} \mathrm{PL}$ of $\mathrm{In}_{0.32} \mathrm{Ga}_{0.68} \mathrm{Sb} / \mathrm{Al}_{0.49} \mathrm{Ga}_{0.51} \mathrm{Sb}$ QW measured under high power non-resonant excitation of $3000 \mathrm{~W} / \mathrm{cm}^{2}$ using $\mathrm{He}-\mathrm{Ne}$ laser $(1.95 \mathrm{eV})$.

will be sensitively dependent on this penetration depth and the diffusion of photo-generated carriers. Under this condition, the PL was measured at the higher excitation power of $3000 \mathrm{~W} / \mathrm{cm}^{2}$ as displayed in Fig. 2(b) and the DAP and $\mathrm{BE} 4-\mathrm{A}^{0}$ peaks originating from the GaSb substrate became more intense. In addition to the three PL peaks found in Fig. 2(a), two more PL peaks are observed at $1544 \mathrm{~nm}$ $(802.9 \mathrm{meV})$ and $1530 \mathrm{~nm}(810.3 \mathrm{meV})$ in Fig. 2(b), which are ascribed to another GaSb exciton bound to neutral acceptor $\left(\mathrm{BE} 2-\mathrm{A}^{0}\right)$ transition $^{28}$ and the free-exciton $\left(\mathrm{E}_{\mathrm{F}}\right)$ transition, ${ }^{26}$ respectively. The free exciton energy of $\mathrm{GaSb}$ together with its binding energy results in the band gap energy of $811.7 \mathrm{meV}$ which agrees well with the previously reported values. ${ }^{29}$ Therefore, it can be concluded that the additional peaks of the DAP, BE2- $\mathrm{A}^{0}, \mathrm{BE} 4-\mathrm{A}^{0}$, and $\mathrm{E}_{\mathrm{F}}$ are emerged from the GaSb substrate due to the carrier diffusion. ${ }^{26-28}$

The dominant PL peak in Fig. 2(a), which was attributed to the QW emission, was further studied on its temperature dependence as shown in Fig. 3(a). The temperature dependence of the measured luminescence peak position of the $\mathrm{In}_{0.32} \mathrm{Ga}_{0.68} \mathrm{Sb} \mathrm{QW}$ is displayed by the red circles in Fig. 3(a) and was fitted using the Varshni empirical expression $^{30}$
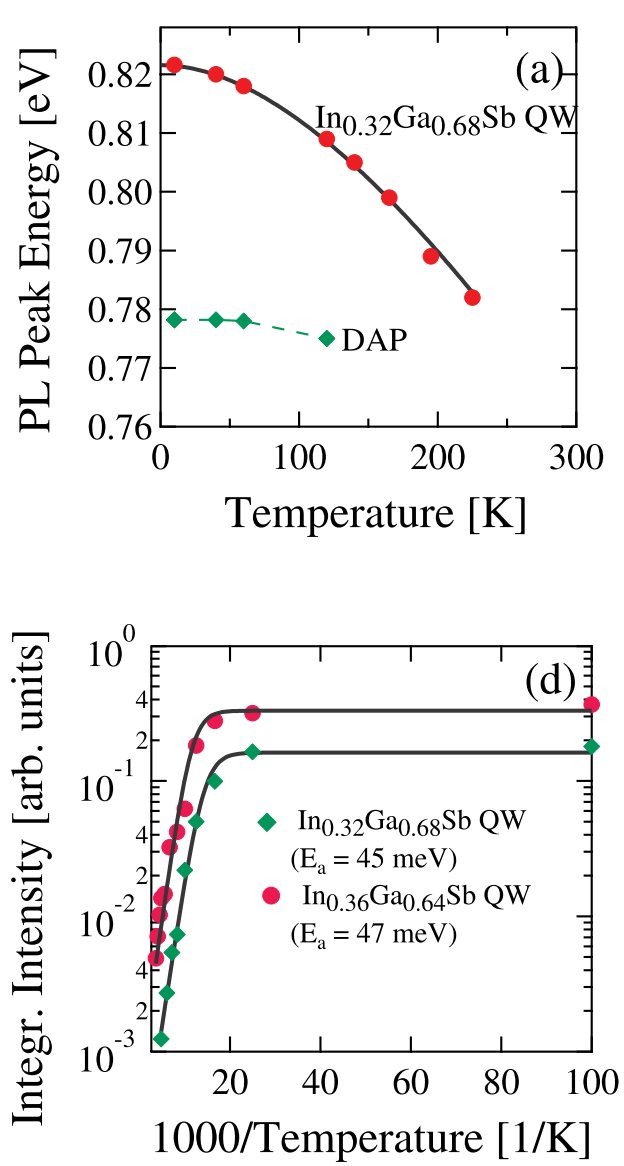
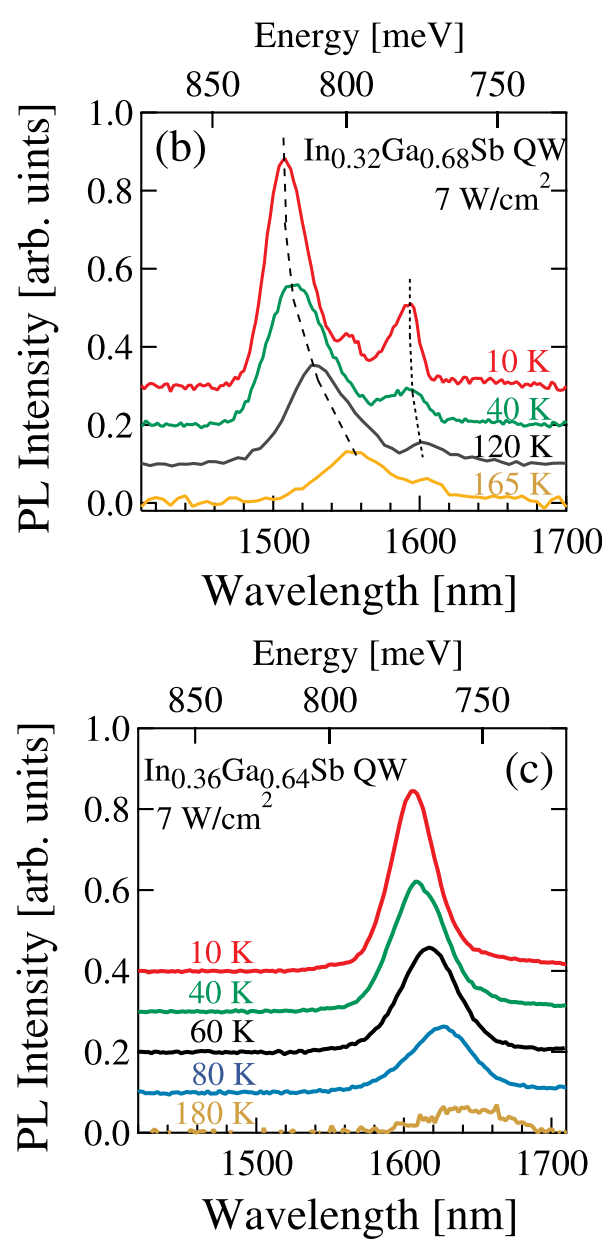

FIG. 3. (a) Temperature dependent energy peak position of $\operatorname{In}_{0.32} \mathrm{Ga}_{0.68} \mathrm{Sb}$ QW (filled circles $(\bullet)$ ) and DAP (filled diamonds $(\bullet)$ ) connected by dashed line. The solid line is obtained by fitting with Varshni relation (Eq. (1)). (b) The temperature dependent PL spectra of $\operatorname{In}_{0.32} \mathrm{Ga}_{0.68} \mathrm{Sb}$ QW for temperatures between 10 and $165 \mathrm{~K}$. The two dotted lines are drawn to highlight the variations of QW PL-peak and DAP PL-peak with temperature. (c) Temperature dependent PL spectra of $\operatorname{In}_{0.36} \mathrm{Ga}_{0.64} \mathrm{Sb} \mathrm{QW}$ for temperatures between 10 and $180 \mathrm{~K}$. Constant offsets were used for visual clarity. (d) Temperature dependent integrated PL intensities of $\operatorname{In}_{0.32} \mathrm{Ga}_{0.68} \mathrm{Sb}$ (diamonds $(\bullet)$ ) and $\mathrm{In}_{0.36} \mathrm{Ga}_{0.648} \mathrm{Sb}$ QWs (circles $\left.(\bullet)\right)$ fitted by Arrhenius law (Eq. (2)) result in the activation energies of 45 and $47 \mathrm{meV}$, respectively. 


$$
E(T)=E_{0}-\frac{\alpha T^{2}}{\beta+T},
$$

where $E_{0}$ is the $0 \mathrm{~K}$ energy gap, $T$ is the temperature in $\mathrm{K}$, $\alpha$ and $\beta$ are the fitting parameters, respectively. The solid line results from the fit using the Varshni parameters of $\alpha=0.39 \mathrm{meV} / \mathrm{K}$ and $\beta=180 \mathrm{~K}$ reported on $\mathrm{InGaSb}{ }^{31}$ The DAP transition shows very weak temperature dependence ${ }^{32}$ up to $90 \mathrm{~K}$ as displayed by the diamonds connected with the dashed line in Fig. 3(a). For the higher temperature, the DAP peak intensity decreases rapidly, while the QW excitonic emission remains dominant. Since DAP undergoes thermal ionization easily due to the small binding energy, the DAP emission intensity rapidly decreases for the higher temperature. $^{32}$ Based on these studies, it can be unambiguously inferred that the PL emission appearing at the wavelength of $1508 \mathrm{~nm}(822 \mathrm{meV})$ at low temperature is the exciton emission in the InGaSb QW.

The temperature dependences of the PL spectra measured on the $\mathrm{In}_{0.32} \mathrm{Ga}_{0.68} \mathrm{Sb}$ and $\mathrm{In}_{0.36} \mathrm{Ga}_{0.64} \mathrm{Sb} \mathrm{QWs}$ are shown in Figs. 3(b) and 3(c), respectively. The QW emission was fitted with the Gaussian line-shape function on each measured spectrum, and its spectrally integrated PL intensity was plotted as a function of inverse temperature in Fig. 3(d). The closed diamonds are for the $\mathrm{In}_{0.32} \mathrm{Ga}_{0.68} \mathrm{Sb} \mathrm{QW}$ and the closed circles are for the $\mathrm{In}_{0.36} \mathrm{Ga}_{0.64} \mathrm{Sb} \mathrm{QW}$. The solid (black) lines are fitting to the experimental data using the Arrhenius equation

$$
I(T)=\frac{I_{0}}{1+B \exp \left(-\frac{E_{a}}{k T}\right)},
$$

where $I_{0}$ is the integrated PL intensity at $0 \mathrm{~K}, E_{\mathrm{a}}$ is the thermal activation energy, $k$ is the Boltzmann constant, and $T$ is the sample temperature in K. $B$ is the dimensionless coefficient which is defined simply as the ratio of carrier capture time and carrier escape time of the related non-radiative process. ${ }^{33}$ For the $\mathrm{In}_{0.32} \mathrm{Ga}_{0.68} \mathrm{Sb} \mathrm{QW}$, the best fit of Eq. (2) yields the activation energy $E_{\mathrm{a}}=45 \pm 9 \mathrm{meV}$ and the corresponding coefficient $B=1270 \pm 210$. For the $\operatorname{In}_{0.36} \mathrm{Ga}_{0.64} \mathrm{Sb}$ QW, the best fit results in the activation energy of $E_{\mathrm{a}}=47 \pm 11 \mathrm{meV}$ with the corresponding coefficient of $\mathrm{B}=615 \pm 93$.

\section{B. Time-resolved PL measurements}

For further investigating the carrier dynamics in the QW structures, time-resolved PL measurements were performed with the 20-ps time resolution. In the following, the measured results on the $\mathrm{In}_{0.32} \mathrm{Ga}_{0.68} \mathrm{Sb} \mathrm{QW}$ are presented and discussed (the $\operatorname{In}_{0.36} \mathrm{Ga}_{0.64} \mathrm{Sb} \mathrm{QW}$ shows qualitatively similar results).

The excitation power dependence of the transient PL decay measured on the $\operatorname{In}_{0.32} \mathrm{Ga}_{0.68} \mathrm{Sb} \mathrm{QW}$ at $4 \mathrm{~K}$ is shown in Fig. 4(a). It is found that the PL transients are well fitted by mono-exponential decay superposed with background noise for all the excitation power. This fitting resulted in the PL lifetime of $\sim 600 \mathrm{ps}$ irrespective of the excitation power. The
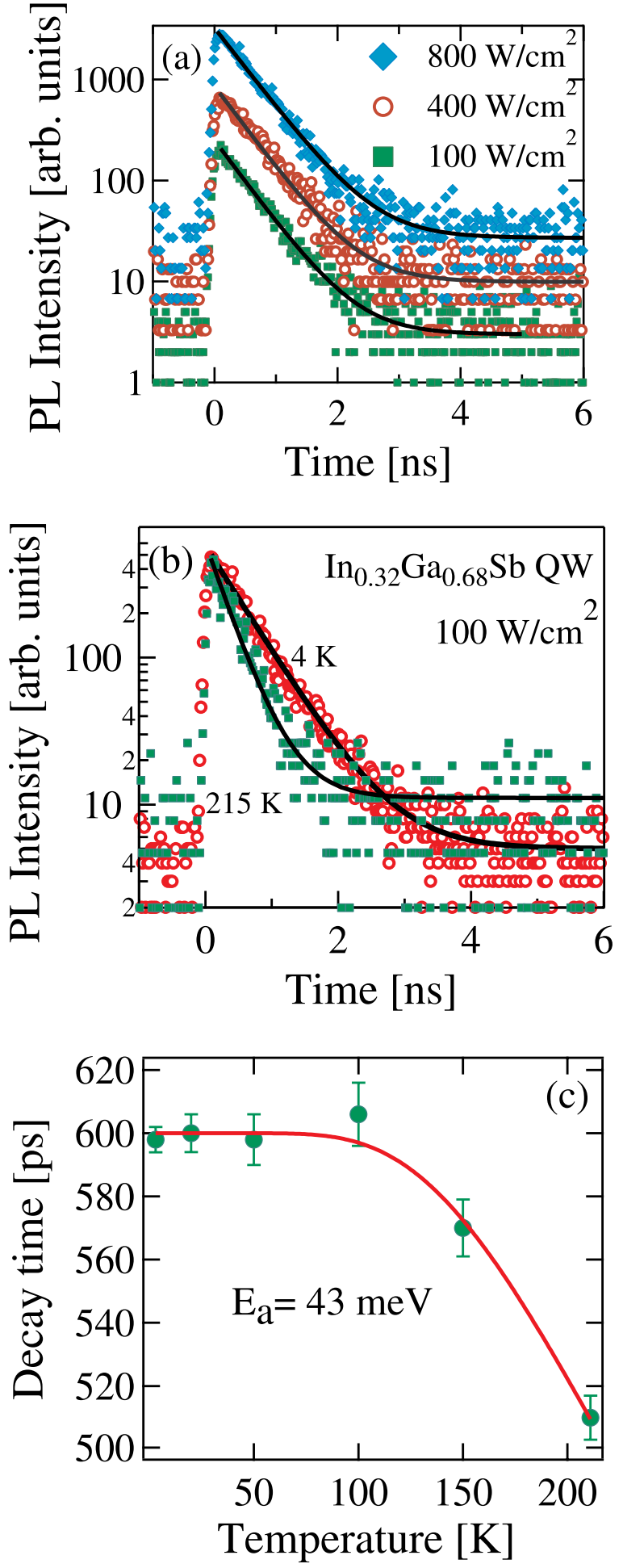

FIG. 4. (a) The excitation power dependent time-resolved PL displayed for three different excitation powers, which shows no variation with the change of power density. The transients were obtained by spectrally binning the data between 1.45 and $1.527 \mu \mathrm{m}$. The solid lines are obtained by fitting the PL decays with mono-exponential. (b) The transient PL traces of $\mathrm{In}_{0.32} \mathrm{Ga}_{0.68} \mathrm{Sb} \mathrm{QW}$ shown for the temperature of $4 \mathrm{~K}$ and $215 \mathrm{~K}$. (c) Temperature dependence of the decay time; the solid line represents the resultant fit using Eq. (3).

temperature dependent time-resolved PL measurements were also performed and the measured results at the temperatures of $4 \mathrm{~K}$ and $215 \mathrm{~K}$ are exemplarily shown in Fig. 4(b). The temperature dependence of the PL lifetime obtained from the 
measurements on the $\operatorname{In}_{0.32} \mathrm{Ga}_{0.68} \mathrm{Sb} \mathrm{QW}$ is summarized in Fig. 4(c). The lifetime remains almost the constant value of $600 \mathrm{ps}$ in the low temperature range below $100 \mathrm{~K}$, while it decreases at the higher temperature. The observed temperature dependence of the lifetime was fitted with the following equation: ${ }^{25}$

$$
\tau(T)=\frac{\tau_{d}}{1+\left(\tau_{d} / \tau_{e}\right) \exp ^{-E_{a} / k T}},
$$

where $T$ is the temperature, $k$ is the Boltzmann constant, $\tau_{d}$ is the recombination lifetime extracted from Fig. 4(a) at low temperature, $E_{a}$ is the activation energy, and $\tau_{e}$ is the escape time of charge carriers from the QW to the barriers. ${ }^{25}$ The fitting of the experimental data results in the escape time of $93 \pm 8 \mathrm{ps}$ and the activation energy of about $43 \mathrm{meV} \pm 11 \mathrm{meV}$. The activation energy of $43 \mathrm{meV}$ derived from the time-resolved measurements is very close to the one of $45 \mathrm{meV}$ previously deduced from the time-integrated PL measurements.

\section{Calculation of $\mathrm{QW}$ band structures based on $\mathrm{PL}$ measurements}

The agreement of the activation energies derived from the time-resolved and time-integrated PL measurements together with the fact that the lifetime does not depend on the excitation power suggests that this thermal activation process is the carrier escape from the QW to the barriers and is responsible for PL quenching. For the complete and selfconsistent understanding of the measured results, the QW confinement energies were calculated by solving the Schrödinger equation for the finite potential wells. First, the deformation potential and the strain contribution to the band structure were considered. The valence-band structure near the zone centre $\left(k_{t}=0\right)$ can be significantly reshaped with strain. The total Hamiltonian which describes the band structure of the strained QW can be expressed as, $H=H_{0}+H_{\mathrm{s}}$, where $H_{0}$ and $H_{\mathrm{s}}$ are the Luttinger-Kohn (LK) Hamiltonian and the strain Hamiltonian, respectively. When a QW is under biaxial strain in the (001) QW plane, the strain components are written as

$$
\begin{gathered}
\epsilon_{x x}=\epsilon_{y y}=\epsilon_{I I}=\frac{\Delta a}{a}, \quad \epsilon_{z z}=-\epsilon_{I I} \frac{2 C_{12}}{C_{11}}, \\
\epsilon_{x y}=\epsilon_{y x}=\epsilon_{z x}=0,
\end{gathered}
$$

where $\Delta a / a$ is the strain due to the lattice mismatch at the hetero-interface and $C_{11}, C_{12}$ are the stiffness constants. The QW plane was considered to be the $x-y$ coordinate plane. For this condition, the strain Hamiltonian $H_{\mathrm{s}}$ is expressed as ${ }^{34}$

$$
H_{s}=-E_{H}-\frac{3}{{ }^{2} h^{2}} E_{U}\left(\overline{\mathrm{L}}_{z}{ }^{2}-\frac{1}{3} \overline{\mathrm{L}}^{2}\right),
$$

where

$$
\begin{gathered}
E_{H}=2 a\left\{\frac{C_{11}-C_{12}}{C_{11}}\right\} \in_{I I}, \\
E_{U}=-b\left\{\frac{C_{11}+2 C_{12}}{C_{11}} \in_{I I}\right\} \in_{I I},
\end{gathered}
$$

where $a$ and $b$ are the hydrostatic and shear deformation potentials, respectively. The matrix element derived from Eq. (5) results in the heavy-hole $(\mathrm{HH})$ band that is uncoupled to the other bands, while the coupling of light-hole ( $\mathrm{LH})$ and spin-orbit split-off (SO) bands occurs by the matrix element $\sqrt{2} E_{U} \cdot{ }^{35}$ The shear deformation potential term $E_{U}$ is proportional to the in-plane strain $\in_{I I}$ as is shown in Eq. (7) and is larger for the larger strain. At $\mathrm{k}_{\mathrm{t}}=0$, the $8 \times 8$ Hamiltonian including the strain terms becomes doubly degenerate $4 \times 4$ matrix. The conduction band in this matrix is decoupled and the Eigen value equation results in the strain contribution to the $\mathrm{HH}$ valence-band maximum (VBM) as ${ }^{35,36}$

$$
E_{d}=-E_{H}-E_{U}
$$

The details of the analysis are narrated in references by Pollak and Cardona ${ }^{35}$ and Suemune. ${ }^{36}$ To evaluate Eq. (8), the material parameters, e.g., the lattice constant, energy gap, and the values of $a, b, C_{11}$, and $C_{12}$ were deduced by the linear interpolation of the corresponding values established for InSb, GaSb, and AlSb. ${ }^{37}$ Using Eqs. (4), (6), (7), and (8), the strain contribution to the HH-VBM of the $\operatorname{In}_{0.32} \mathrm{Ga}_{0.68} \mathrm{Sb}$ and $\mathrm{In}_{0.36} \mathrm{Ga}_{0.64} \mathrm{Sb}$ QWs is calculated as $E_{d}=-E_{H}-E_{U}=-72 \mathrm{meV}$ and $E_{d}=-E_{H}-E_{U}=-78 \mathrm{meV}$, respectively

We have precisely determined the well thickness and the alloy compositions with the XRD measurements in Sec. II, and therefore, the unstrained energy gaps of the $\operatorname{In}_{0.32} \mathrm{Ga}_{0.68} \mathrm{Sb} \mathrm{QW}$ and the $\mathrm{Al}_{0.49} \mathrm{Ga}_{0.51} \mathrm{Sb}$ barriers are given as $538 \mathrm{meV}$ and $1203 \mathrm{meV}$, respectively, from the reported materials data. ${ }^{37}$ Including the calculated strain contribution, the QW energy gap increases to $610 \mathrm{meV}$. In the present InGaSb/AlGaSb common-anion heterostructures, it is known that the band offset is localized to the conduction band. Then it is natural to assume that the thermal activation energy of $45 \mathrm{meV}$ for the carrier escape from the QW to the barriers is dominated in the valence band. Under the present low excitation condition, it will favourably be the hole escape from the QW ground energy state to the AlGaSb barriers. The measured QW exciton emission energy was $822 \mathrm{meV}$. Consideration of the small exciton binding energy $(1.14 \mathrm{meV})^{38,39}$ leads to the transition energy of $823 \mathrm{meV}$ from the conduction-band to the valence-band QW energy states. Based on the above available information, we have calculated the QW confinement energies by solving the Schrödinger equation by varying the band offset values. Using the iteration method, it is found that the small valanceband offset of $13 \%$ gives the most precise agreement with the experimentally observed QW emission energy. This small valance-band offset is comparable to the previously published values. ${ }^{40}$ Our calculated band parameters are summarized in Fig. 5 and the calculated transition energy is given by

$$
\begin{aligned}
E_{T} & =E_{e}^{1}+E_{g}-E_{d}+E_{h h}^{1} \\
& =(183+538+72+30) \mathrm{meV}=823 \mathrm{meV},
\end{aligned}
$$

where $E_{e}{ }^{1}=183 \mathrm{meV}$ is the ground-state electron confinement energy, $E_{h h}{ }^{1}=30 \mathrm{meV}$ is the ground-state $\mathrm{HH}$ confinement energy, $E_{g}=538 \mathrm{meV}$ is the energy gap of the $\mathrm{In}_{0.32} \mathrm{Ga}_{0.68} \mathrm{Sb} \mathrm{QW}$, and $E_{d}=-72 \mathrm{meV}$ is the strain contribution. 


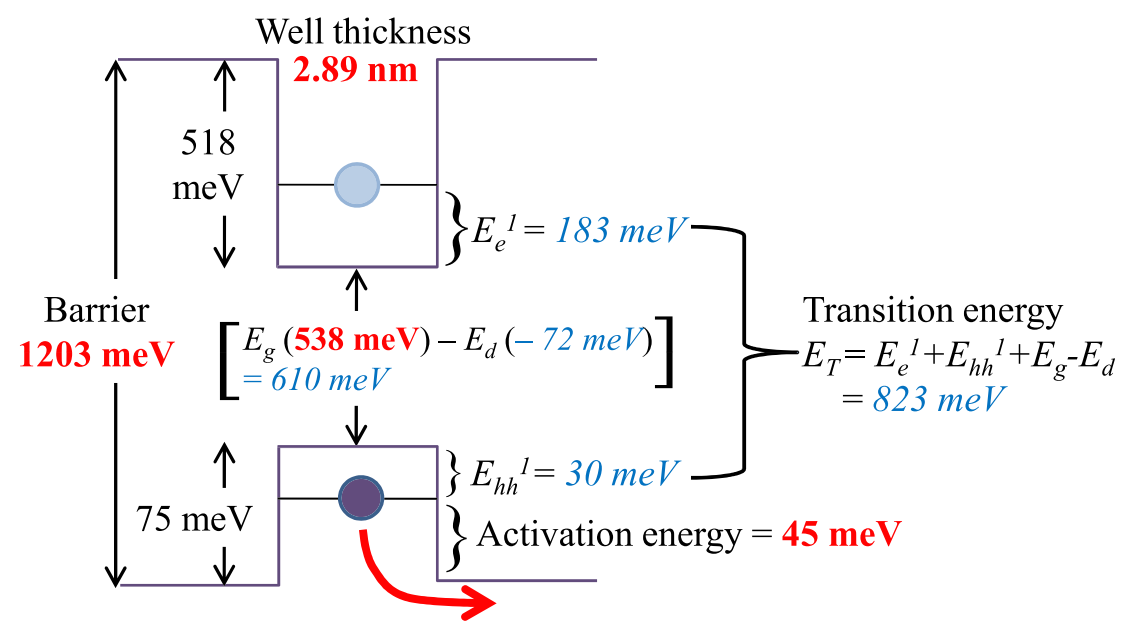

FIG. 5. The illustration of calculated band diagram and confinement energy of the strained $\mathrm{In}_{0.32} \mathrm{Ga}_{0.68} \mathrm{Sb} / \mathrm{Al}_{0.493} \mathrm{Ga}_{0.507} \mathrm{Sb} \mathrm{QW}$ with the inclusion of deformation potential $\left(E_{d}\right)$. The values given in red (bold) are input parameters extracted from individual measurements while values given in blue (italic) result from calculations.

\section{Discussion}

The present self-consistent results confirm that the dominant PL quenching mechanism is the hole escape from the valence-band QW energy state to the barriers. The nature of the carrier escape mechanism has been discussed with the ratio of ${ }^{41-44}$

$$
v=E_{a} / \Delta E
$$

where $E_{\mathrm{a}}$ is the measured thermal activation energy and $\Delta E$ is the optical gap between the emitting states and the higher energy states. Equation (10) classifies three different scenarios of charge carrier escape. For $\nu=1$, an escape process of fully correlated electron-hole pairs, i.e., bound excitons, is described, while $\nu$ less than $1 / 2$ is described for single carrier escape. In the case of correlated electron-hole (e-h) escape, $\nu=1 / 2$ is satisfied. ${ }^{42}$ In the case of $\mathrm{InAs} / \mathrm{InGaAlAs}{ }^{44}$ and InAs/InP ${ }^{41}$ emitting in the $1.55-\mu \mathrm{m}$ band, the authors concluded $\nu=1 / 2$, that is, the mechanism behind the thermal escape was suggested to be a correlated e-h pair escape. In our present InGaSb/AlGaSb, QW sample also emitting in the $1.55-\mu \mathrm{m}$ band, $\nu=0.12$ is obtained and thereby the single carrier (hole) escape mechanism dominates. The main factor for this different escape mechanism is the band offsets. In the case of the InAs/InGaAlAs and InAs/InP heterostructures, the band offset is almost equally divided to the conduction and valence bands, while the band offset is localized to the conduction band in the present case of $\mathrm{InGaSb} / \mathrm{AlGaSb}$.

Finally, we want to discuss the relation to the Auger recombination process which is commonly considered for narrow-band-gap semiconductors. This non-radiative Auger recombination is a density dependent mechanism which usually increases with decreasing band-gap energy and is typically found to be increased monotonically with temperature and carrier density. ${ }^{45,46}$ Main Auger recombination processes are divided into two processes of the conduction (C)-C-Chole $(\mathrm{H})(\mathrm{CCCH})$ transition and $\mathrm{C}-\mathrm{H}-\mathrm{H}-\mathrm{SO}(\mathrm{S})(\mathrm{CHHS})$ transition. $^{47}$ The $\mathrm{CCCH}$ process involves one electron transition within the conduction band and another electron transition to the valence band. The CHHS process involves one hole transition to the conduction band and another hole transition to the SO band. In the case of the Sb-based semiconductors, the SO energy is very large, such as $820 \mathrm{meV}$ for $\mathrm{GaSb}$, and is compat- ible to their energy gaps, and the CHHS process dominates because the conservation of energy and momentum for the Auger transition is easier. This CHHS process is critically dependent on the hole concentration. ${ }^{47}$

From the time-resolved PL measurements discussed in Sec. IV B, the PL lifetimes measured on the QW sample did not show any change with increasing the excitation power, which apparently implies that the QW does not follow the typical density dependence of the Auger recombination. However, the hole leakage that limits the maximum hole concentration is closely related to this phenomenon. In Fig. 3(a), the integrated PL intensity initiates to quench above $50 \mathrm{~K}$, while the PL decay time remains the same up to $100 \mathrm{~K}$. This difference suggests that the hole concentration is kept nearly the same in spite of the hole escape at around $100 \mathrm{~K}$, which keeps the Auger recombination rate nearly constant. At the higher temperature, it is probable that the energy broadening increases the Auger recombination rate as well as the thermally activated hole escape. However, from the temperature dependent time-resolve PL measurements, it is noticed that the PL decay time decreased from $600 \mathrm{ps}$ at $4 \mathrm{~K}$ to $510 \mathrm{ps}$ at $220 \mathrm{~K}$, which is rather small variation in comparison to the typical reported 3-4 times drastic decrease of the Auger recombination time with temperature. ${ }^{48}$ This will be attributed to the limited hole concentration by the hole escape in the present situation.

\section{CONCLUSIONS}

Photoluminescence quenching mechanism of $\operatorname{In}_{\mathrm{x}} \mathrm{Ga}_{1-\mathrm{x}}$ $\mathrm{Sb} / \mathrm{Al}_{\mathrm{y}} \mathrm{Ga}_{1-\mathrm{y}} \mathrm{Sb} \mathrm{QWs}$ was investigated. The In and $\mathrm{Al}$ concentrations as well as the QW thicknesses were precisely determined with the XRD measurements. Temperature dependent time-integrated and time-resolved PL spectroscopies resulted in the thermal activation energies of $\sim 45 \mathrm{meV}$, and the overall self-consistent calculation of the band parameters based on the measured physical values confirmed that the activation energies are due to the hole escape from the $\mathrm{QW}$ to the barriers. The relation of the present single carrier escape mechanism with the other escape mechanisms reported with other material systems emitting in the $1.55-\mu \mathrm{m}$ band was discussed based on the estimated band offset. The relation between the present thermal hole escape and the Auger recombination was also discussed. 


\section{ACKNOWLEDGMENTS}

This work was partially supported by the Grand-in-Aid for Scientific Research (S), No. 24226007 from the Ministry of Education, Culture, Sports, Science and Technology-Japan, and SCOPE (Strategic Information and Communications R\&D Promotion Programme) from the Ministry of Internal Affairs and Communications, Japan. N.A.J. acknowledges financial support via a MEXT scholarship.

${ }^{1}$ J. A. Gupta, P. J. Barrios, J. Lapointe, G. C. Aers, and C. Storey, Appl. Phys. Lett. 95, 041104 (2009).

${ }^{2}$ H. I. Schiff, G. I. Mackay, and J. Bechara, "The use of tunable diode laser absorption spectroscopy for atmospheric measurements," in Air Monitoring by Spectroscopic Techniques, Chemical Analysis Series Vol. 127, edited by M. W. Sigrist (John Wiley and Sons, 1994), pp. 239-318.

${ }^{3}$ A. I. Nadezhdinskii and A. M. Prokhorov, Proc. SPIE 1724, 2 (1992).

${ }^{4}$ J.-C. Nicolas, A. N. Baranov, Y. Cuminal, Y. Rouillard, and C. Alibert, Appl. Opt. 37, 7906 (1998).

${ }^{5}$ G. W. Charache, P. F. Baldasaro, L. R. Danielson, D. M. DePoy, M. J. Freeman, C. A. Wang, H. K. Choi, D. Z. Garbuzov, R. U. Martinelli, V. Khalfin, S. Saroop, J. M. Borrego, and R. J. Gutmann, J. Appl. Phys. 85, 2247 (1999).

${ }^{6}$ H. K. Choi, C. A. Wang, G. W. Turner, M. J. Manfra, D. L. Spears, G. W. Charache, L. R. Danielson, and D. M. Depoy, Appl. Phys. Lett. 71, 3758 (1997).

${ }^{7}$ K. Akahane, N. Yamamoto, S.-I. Gozu, A. Ueta, and N. Ohtani, Thin Solid Films 515, 4467 (2007).

${ }^{8}$ E. Hall, H. Kroemer, and L. A. Coldren, Electron. Lett. 35, 425 (1999).

${ }^{9}$ O. Blum, J. F. Klem, K. L. Lear, G. A. Vawter, and S. R. Kurtz, Electron. Lett. 33, 1878 (1997).

${ }^{10}$ P. S. Dutta, H. L. Bhat, and V. Kumar, J. Appl. Phys. 81, 5821 (1997).

${ }^{11}$ N. Yamamoto, K. Akahanea, S. Gozua, A. Uetaa, N. Ohtanib, and M. Tsuchiyaa, Proc. SPIE 6393, 63930A (2006).

${ }^{12}$ S. H. Huang, G. Balakrishnan, A. Khoshakhlagh, A. Jallipalli, L. R. Dawson, and D. L. Huffaker, Appl. Phys. Lett. 88, 131911 (2006).

${ }^{13}$ J. Tatebayashi, A. Jallipalli, M. N. Kutty, S. H. Huang, G. Balakrishnan, L. R. Dawson, and D. L. Huffaker, Appl. Phys. Lett. 91, 141102 (2007).

${ }^{14}$ J. Koeth, R. Dietrich, and A. Forchel, Appl. Phys. Lett. 72, 1638 (1998).

${ }^{15}$ N. Bertru, A. Baranove, Y. Cuminal, G. Almuneau, F. Genty, A. Joullié, O. Brand, A. Mazuelas, and K. H. Ploog, Semicond. Sci. Technol. 13, 936 (1998).

${ }^{16}$ A. D. Andreev, E. P. O’Reilly, A. R. Adams, and T. Ashley, Appl. Phys. Lett. 78, 2640 (2001).

${ }^{17}$ Y.-Y. Lai, J. M. Yarborough, Y. Kaneda, J. Hader, J. V. Moloney, T. J. Rotter, G. Balakrishnan, C. Hains, and S. W. Koch, IEEE Photon. Technol. Lett. 22, 1253 (2010).

${ }^{18}$ T. J. Rotter, J. Tatebayashi, P. Senanayake, G. Balakrishnan, M. Rattunde, J. Wagner, J. Hader, J. V. Moloney, S. W. Koch, L. Ralph Dawson, and D. L. Huffaker, Appl. Phys. Express 2, 112102 (2009).
${ }^{19}$ K. O’Brien, S. J. Sweeney, A. R. Adams, B. N. Murdin, A. Salhi, Y. Rouillard, and A. Joullié, Appl. Phys. Lett. 89, 051104 (2006).

${ }^{20}$ Y. Jiang, M. C. Teich, and W. I. Wang, Appl. Phys. Lett. 57, 2922 (1990)

${ }^{21}$ S. Anikeev, D. Donetsky, G. Belenky, S. Luryi, C. A. Wang, J. M. Borrego, and G. Nichols, Appl. Phys. Lett. 83, 3317 (2003).

${ }^{22}$ A. Laurain, J. Hader, Y.-Y. Lai, T.-L. Wang, J. M. Jarborough, G. Balakrishnan, T. J. Rotter, P. Ahirwar, and J. V. Moloney, Proc. SPIE 8242, 82420S (2012).

${ }^{23}$ L. Shterengas, G. L. Belenky, J. G. Kim, and R. U. Martinelli, Semicond. Sci. Technol. 19, 655 (2004).

${ }^{24}$ L. Shterengas, G. Belenky, M. V. Kisin, and D. Donetsky, Appl. Phys. Lett. 90, 011119 (2007).

${ }^{25}$ G. Rainò, A. Salhi, V. Tasco, R. Intartaglia, R. Cingolani, Y. Rouillard, E. Tournié, and M. De Giorgi, Appl. Phys. Lett. 92, 101931 (2008).

${ }^{26}$ S. C. Chen and Y. K. Su, J. Appl. Phys. 66, 350 (1989).

${ }^{27}$ M. Lee, D. J. Nicholas, K. E. Singer, and B. Hamilton, J. Appl. Phys. 59, 2895 (1986).

${ }^{28}$ Y. K. Su and S. M. Chen, J. Appl. Phys. 73, 8349 (1993).

${ }^{29}$ C. Ghezzi, R. Magnanini, A. Parisini, B. Rotelli, and L. Tarricone, Phys. Rev. B 52, 1463 (1995).

${ }^{30}$ Y. P. Varshni, Physica (Amsterdam) 34, 149 (1967).

${ }^{31}$ M. Motyka, R. Kudrawiec, J. Misiewicz, M. Hümmer, K. Rößner, T. Lehnhardt, M. Müller, and A. Forchel, J. Appl. Phys. 103, 113514 (2008).

${ }^{32}$ J. H. Park, T. K. Lee, Y. K. Noh, M. D. Kim, and E. Oh, J. Appl. Phys. 105, 043516 (2009).

${ }^{33}$ E. C. Le Ru, J. Fack, and R. Murray, Phys. Rev. B 67, 245318 (2003).

${ }^{34}$ G. E. Pikus and G. L. Bir, Fiz. Tverd. Tela (Leningrad) 1, 1642 (1959) [Sov. Phys.-Solid State 1, 1502 (1959)].

${ }^{35}$ F. H. Pollak and M. Cardona, Phys. Rev. 172, 816 (1968).

${ }^{36}$ I. Suemune, Phys. Rev. B 43, 14099 (1991).

${ }^{37}$ I. Vurgaftman, J. R. Meyer, and L. R. Ram-Mohan, J. Appl. Phys. 89, 5815 (2001)

${ }^{38}$ Z. M. Fang, K. Y. Ma, D. H. Jaw, R. M. Cohen, and G. B. Stringfellow, J. Appl. Phys. 67, 7034 (1990).

${ }^{39}$ G. Bastard, E. E. Mendez, L. L. Chang, and L. Esaki, Phys. Rev. B 26, 1974 (1982).

${ }^{40}$ M. Motyka, G. Sek, K. Ryczko, J. Misiewicz, S. Belahsene, G. Boissier, and Y. Rouillard, J. Appl. Phys. 106, 066104 (2009).

${ }^{41}$ G. Gelinas, A. Lanacer, R. Leonnelli, R. A. Masut, and P. J. Poole, Phys. Rev. B 81, 235426 (2010).

${ }^{42}$ W. D. Yang, R. R. Lowe-Webb, H. Lee, and P. C. Sercel, Phys. Rev. B 56, 13314 (1997).

${ }^{43}$ P. Michler, A. Hangleiter, M. Moser, M. Geiger, and F. Scholz, Phys. Rev. B 46, 7280 (1992).

${ }^{44}$ C. Hermannstädter, N. A. Jahan, J.-H. Huh, H. Sasakura, K. Akahane, M. Sasaki, and I. Suemune, New J. Phys. 14, 023037 (2012).

${ }^{45}$ D.-J. Jang, M. E. Flatté, C. H. Grein, J. T. Olesberg, T. C. Hasenberg, and T. F. Boggess, Phys. Rev. B 58, 13047 (1998).

${ }^{46}$ L. C. Chiu and A. Yariv, IEEE J. Quantum Electron. 18, 1406 (1982).

${ }^{47}$ I. Suemune, Appl. Phys. Lett. 55, 2579 (1989).

${ }^{48}$ M. E. Flatté, C. H. Grein, T. C. Hasenberg, S. A. Anson, D.-J. Jang, J. T. Olesberg, and T. F. Boggess, Phys. Rev. B 59, 5745 (1999). 